\title{
Submucosal tunnel dissection through the pyloric ring for removal of a sessile duodenal adenoma adjacent to a scar
}

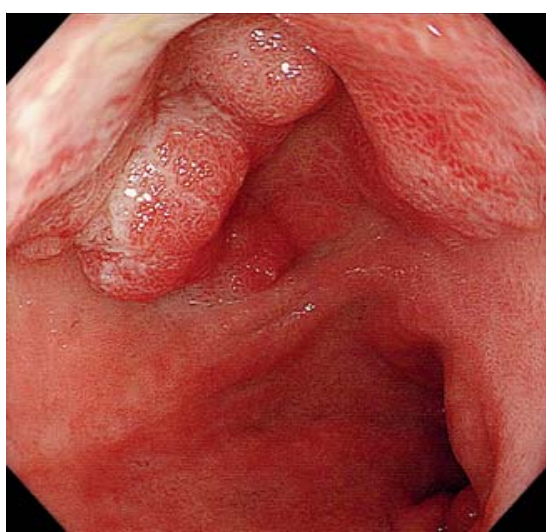

Fig. 1 White light photomicrograph of a sessile polyp on the front wall of the duodenal bulb in a 52-year-old man.

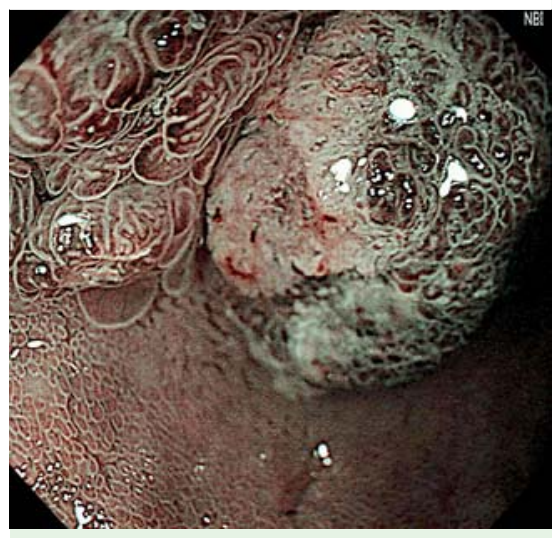

Fig. 2 Magnifying narrowband image of the lesion.

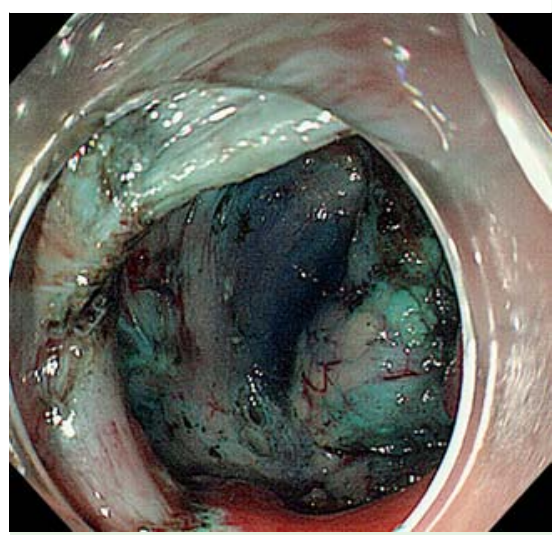

Fig. 3 Submucosal tunnel dissection through the pyloric ring for removal of the lesion.

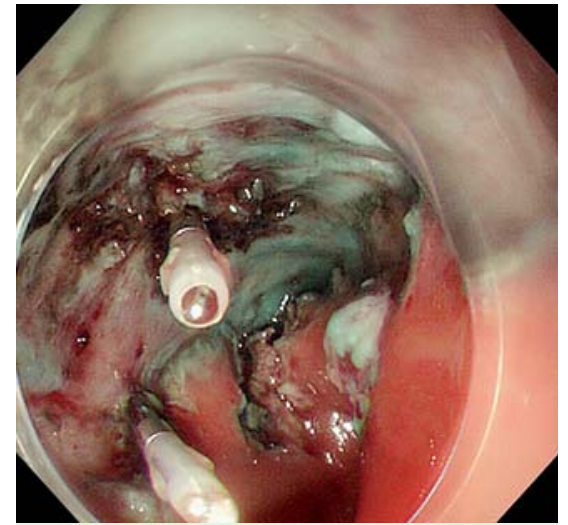

Fig. 4 Wound surface after completed endoscopic submucosal dissection.

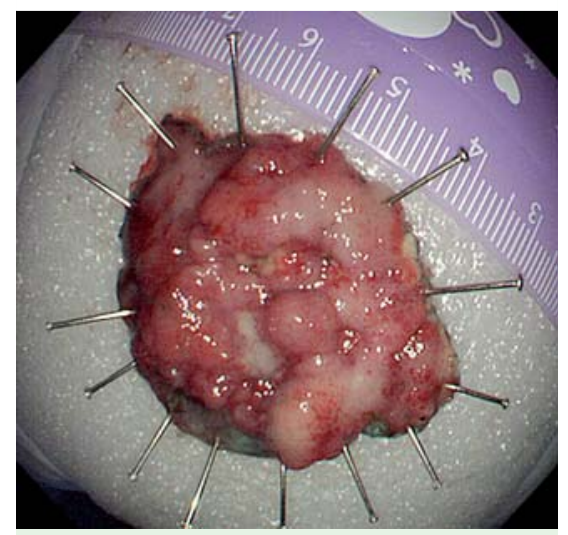

Fig. 5 The resected specimen.

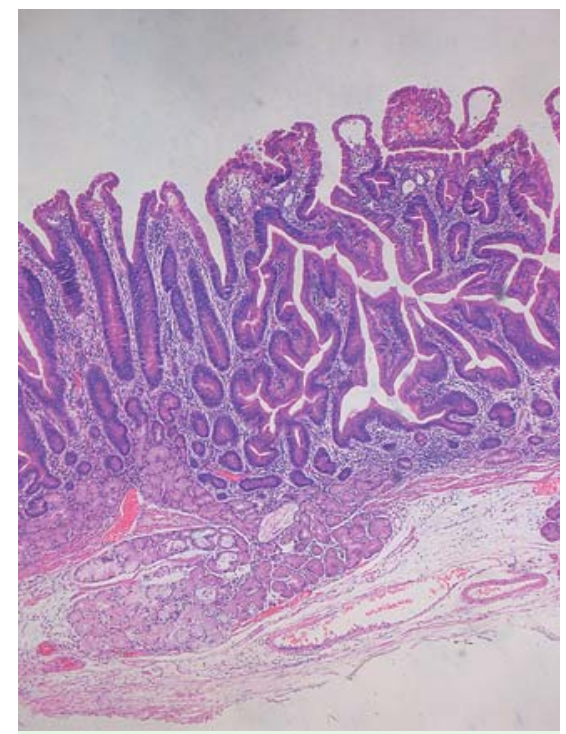

Fig. 6 Histology slide of the lesion (magnification $\times 100$ ).
Endoscopic submucosal dissection (ESD) for duodenal neoplasms is generally difficult because of the thin wall and narrow lumen of the duodenum [1]. A scar near the neoplasm due to chronic ulcer or biopsies often makes the situation more formidable. We report the case of a duodenal adenoma in a 52-year-old man. Esophagogastroduodenoscopy (EGD) had shown a sessile polyp on the front wall of the duodenal bulb, with an estimated size of $4 \times 3 \mathrm{~cm}$ ( $\bullet$ Fig. 1 ). The lesion extended to the pyloric canal, and there was a peptic ulcer scar near the polyp.Magnifying narrowband imaging showed a tubular pit pattern and irregular villous structure ( $\odot$ Fig. 2). Biopsy demonstrated that the polyp was a tubulovillous adenoma with moderate dysplasia. ESD was employed for its removal. Sodium hyaluronate was used for submucosal injection, and a Dual-Knife (Olympus Corp., Tokyo, Japan) was used for mucosal resection and submucosal dissection ( $\bullet$ Video $\mathbf{1}$ ).

It has previously been reported in the literature that ESD using the retroflexion maneuver is more effective for tumors involving the pyloric canal [2]. However, the margin of the lesion in our patient could not be adequately reached with retroflexion, and the submucosal dissection plane could not be obtained because of the bulbous deformity created by the scar and the large size of the lesion. We therefore performed ESD from the gastric side first with a forward view, dissecting a submucosal tunnel through the pyloric ring $(\bullet$ Fig. 3). As expected, the part adjacent to the scar was not lifted well even when sodium hyaluronate was injected, and arterial bleeding occurred frequently during dissection of this part. Two mini-perforations were encountered during hemostasis, and clips were used for closure after adequate submucosal dissection ( $\bullet$ Fig. 4). En bloc resection was achieved and the size of the resected specimen was $4.5 \times 3.5 \mathrm{~cm}$ ( Fig.5). The whole procedure time was 157 minutes. The histologic study showed complete resection of a tubulovillous adenoma with mild to moderate dysplasia ( $\bullet$ Fig. 6 ). The patient was successfully treated conservatively during a hospital stay of 8 days. No serious complication was seen thereafter. The last fol-

\section{Video 1}

Submucosal tunnel dissection through the pyloric ring for removal of a sessile duodenal adenoma adjacent to a scar. 
low-up EGD showed no residual tumor or recurrence.

Endoscopy_UCTN_Code_TTT_1AO_2AG

\section{Competing interests: None}

\section{P. Jin ${ }^{1,2}$, J. Sheng ${ }^{1}$, A. Li ${ }^{1}$, K. I. Fu ${ }^{1}$}

${ }^{1}$ Department of Gastroenterology, Beijing Military General Hospital, Beijing 100700 ,

China

2 Third Military Medical University, Chongqing 400038, China

\section{References}

1 Jung JH, Choi KD, Ahn JY et al. Endoscopic submucosal dissection for sessile, nonampullary duodenal adenomas. Endoscopy 2013; 45: $133-135$

2 Park JC, Kim JH, Youn YH et al. How to manage pyloric tumours that are difficult to resect completely with endoscopic resection: comparison of the retroflexion vs. forward view technique. Dig Liver Dis 2011; 43: 958-964

\section{Bibliography}

DoI http://dx.doi.org/

10.1055/s-0033-1344557

Endoscopy 2013; 45: E303-E304

(c) Georg Thieme Verlag KG

Stuttgart · New York

ISSN 0013-726X

\section{Corresponding author}

\section{K. I. Fu, MD}

Department of Gastroenterology Beijing Military General Hospital

Nanmenchang 5\#

Dongcheng District

Beijing 100700

China

fukuangi@hotmail.com 